\title{
Mum's the word: confidentiality and incest
}

\author{
Roger Higgs Case conference editor
}

\section{Case conference editor's note}

This case conference was held on Tuesday 20 September 1983 at King's College School of Medicine and Dentistry.

\section{Tina}

A thirteen-year-old girl, Tina, was brought by her friend to casualty, at five o'clock one winter's evening. She had taken an overdose of aspirin, not enough to threaten her life, but requiring admission. She would not discuss the reasons for her action with anyone but became very withdrawn on the ward and declared 'it was the only way out'.

In the second interview with the psychiatrist, after he had assured her that her confidence would be entirely respected, she haltingly revealed the background to her suicide attempt.

She came from a family of four. They had moved five years before from the North of England, just after her younger brother John was born. Her mother became disturbed after the boy was born, and rapidly deteriorated to the point where she needed inpatient psychiatric care. She was diagnosed as schizophrenic, is currently in institutional care, and seems unlikely to return to the family. Her sister moved down to be with the family to take on John's care, but died of a subarachnoid haemorrhage when John was two. Tina had difficulty in describing her feelings about her aunt, but still felt very distressed about her mother's illness. She made it clear that she felt responsible for John's care and upbringing, and had willingly become the housewife.

Not long after her twelfth birthday she noted a change in her father. A welder in a local firm, he had begun to drink more heavily. He made sexual advances to her. At the time of her overdose he had become redundant and was waiting for her whenever she returned from school. Nothing in the experience was pleasant, but she felt trapped by her duty to her mother and to John, and was still, though only just, fond of her

\section{Key words}

Incest; confidentiality; patient-doctor relationship. father and sorry for his loneliness. Her teacher had commented on the drop in her standard of work and having to come home from school to look after the family had not enabled her to continue as a girl guide or in her school choir, and she had lost a lot of friends. She had one close friend, who had brought her to Casualty, but she felt that she could not confide in her for her friend's sake. The evening before she came to hospital her father had suggested she should have her mildly bat ears corrected.

She regularly reminded the psychiatrist about his promise of total confidence. She was desperate to go home now that she was over the immediate ill-effects of the overdose, and asked to be discharged. She said her father had visited earlier, but no one had seen him.

Please respond to this case as you wish, but no further details are available. In particular, you are asked to consider yourself in the psychiatrist's position. What should he or she do, and why?

The above account is factual, but in addition you are asked to comment separately on three hypothetical situations.

1. What would you do if she asked you to press for her ear operation?

2. What would your response be if you knew she had recently missed a period and thought she was pregnant?

3. How would you react later if you discovered she had been seen in Casualty with bleeding from a torn vaginal wall?

\section{Commentary 1}

\section{Baum Professor of Surgery, King's College Hospital, London}

If I was the psychiatrist and I chose to refer the patient to the surgeon I would have to confide in the surgeon I couldn't say, please see and advise - I would have to explain the background, otherwise the surgeon could not fulfil his role in deciding whether or not this was a true cosmetic problem which in itself could produce psychological symptoms or whether the request to change the body image of the girl was another expression of the appalling background social 
circumstances. So, I make the decision as a psychiatrist whether or not to refer depending on whether or not I am prepared to go in breach of confidence. So, immediately, we are up against this clash of moral imperatives, on the one hand you want to respect the confidence of this girl, but on the other hand you may feel that you need help from a surgical colleague and you cannot do your best for the patient without a breach of confidence. That is a difficult decision for the psychiatrist, but if I was the surgeon on the receiving end, I would expect my colleague to provide all RELEVANT INFORMATION, if he chose to refer the girl to me.

The second question is easy. I would refer her to Professor Campbell, who is the Professor of Obstetrics and Gynaecology. The girl has to be looked after by an obstetrician and again, what I said before regarding the referral of the girl to the surgeon follows for referring the girl to an obstetrician. I am sure Professor Campbell would feel the same way as I do if this girl were pregnant and if one is considering reasons for aborting or not aborting it is absolutely essential that the whole background is known to the obstetrician. So, although there again appears to be a clash of moral imperatives, I wonder how sincere the girl was in requesting the confidence. The rather trivial attempt at suicide, if it was a trivial attempt I would interpret as a cri de coeur 'please help me, things are so bad I have to draw attention to my problems', and I would be prepared to interpret that as saying that she really does want help from as many people as possible and my conscience would be clear about sharing her problems with my professional colleagues, a surgeon on the one hand and an obstetrician on the other.

The final question is very difficult and I don't know my position on this one. The initial reaction is one of absolute fury - you want to kill someone but of course you don't! We have to recognise this response within ourselves. It comes from the fact that incest really is the last taboo subject - you can talk and joke about almost anything now but incest is still not spoken about, and that means that we tend to overreact to problems of incest. At the weekend I consulted my brother who is a paediatrician at Oxford. He tells me incest is not an uncommon problem. His advice to me when responding to my question was that once you had called in help from the community services to go softly, softly. The worst thing you could do to that girl, was to create an enormous brouhaha involving the police because that would aggravate the issue. There I am speaking not out of my own experience or expertise, but just out of second or third-hand information.

\section{Commentary 2}

Christopher Bass Consultant Psychiatrist, King's College Hospital, London

Question 1. Tina's bat ears are the least of her problems. I would strongly discourage any form of $\frac{\text { TI }}{F}$ cosmetic operation at this stage.

Question 2. I would ask Tina if she had had sexual $\overrightarrow{\vec{F}}$ relations with anyone. If she denied this, which is theo most likely response, I would take a urine sample for $\bar{O}$ pregnancy test and blood samples to exclude sexually $\frac{\bar{c}}{\bar{\sigma}}$ transmitted diseases (STD) eg syphilis.

Question 3. My answer to this question is informed by the knowledge that sex with a minor is an offence, $\vec{\circ}$ punishable by a custodial sentence. The psychiatrist $\overrightarrow{\vec{\omega}}$ could, therefore, inform the local authority social $\stackrel{\omega}{\omega}$ services department, which could in turn inform the $\overline{3}$ police. (In all probability the social services would $\Phi$ already be aware of this family's difficulties, although $\vec{\exists}$ for the purposes of this discussion I am assuming they are not). However, this course of action could have $\vec{\circ}$ disastrous consequences for the family: prosecution of the father leading to a prison sentence and the taking into care of Tina and her brother, perhaps into different institutions.

If the psychiatrist does not take this course of action, $\vec{\oplus}$ however, he knows that Tina will continue to run the. risk of being exposed to a father who abuses alcohol, behaves in a menacing manner at home and who mays continue to sexually abuse her. Thus, not to refer to the social services could have equally disastrous consequences for Tina. This highlights the essential ${ }_{\Omega}^{\mathbb{Q}}$ dilemma in this case: how to reconcile the needs of the $\Rightarrow$ patient (who wants to keep the family together), with the need to protect her from the physical and emotional consequences of sexual abuse.

Unfortunately, our psychiatrist has promised confidentiality, not always a wise decision with young adolescents since it can lead to manipulation of thedoctor by the patient, and may encourage the doctor to make promises that he cannot always keep.

I would inform Tina that I respected her need for confidentiality, but only on condition that I spoke to응 her father before her discharge from hospital: in fact, $\mathrm{I}_{\supset}$ would make her discharge from hospital conditionalo upon his collecting her from the ward. At this stage $I_{N}$ can envisage an important practical problem: where should Tina be managed? I would do everything within $\tilde{O}^{\circ}$ my power to keep Tina in the medical ward rather than ${ }_{\omega}^{N}$ refer her to the local adolescent psychiatric service. Sheo would need to remain in hospital in order for ao therapeutic alliance to become established.

In my interview with her father I would not adopt an $\stackrel{+}{+}$ adversarial role. Rather, I would ask exploratoryo questions about his domestic life, the impact of recento unemployment, and Tina's role as mother $\mathbb{R}$ housekeeper. I would also ask him to suggest possible $\overrightarrow{0}$ reasons why Tina took the drug overdose. Myo questions would be phrased in such a way as to give him an opportunity to discuss the difficulties he musto have experienced coping with a young family withs limited resources and a wife in a mental asylum. 
would not at this stage inform him that Tina had, in all likelihood, been sexually abused. He is likely to be aware of this and also that I know about it. I would be quite explicit with him and inform him of the two options open to me:

(i) that in view of Tina's drug overdose, his financial difficulties and unemployment, that it might be appropriate to request the assistance of the local social services;

(ii) that I would be prepared to help both Tina and himself resolve their domestic and emotional problems in a number of therapeutic meetings.

If, as seems most likely, he chose the second option, I would at this stage enlist the help of a female coworker: either a psychologist or social worker prepared to co-operate in the therapeutic contact. I would then plan a number of short-term goals, which would include a number of explicit contracts, viz: father to stop harassing Tina at school and to reduce his alcohol consumption; Tina to involve herself less in domestic and maternal chores and to resume her own social life, attending girl guides, choir etc.

Meetings with Tina and her father would take place twice weekly in the first instance, and they would be interviewed separately as well as together. I would also like to interview Tina's brother John, who might be able to supply important information about any changes that were taking place at home. The schoolteacher would also be able to provide useful information about Tina's school performance and behaviour.

If no changes had occurred after about four to six weeks of this approach, and there was evidence that physical or sexual abuse of Tina was continuing, I would have no hesitation in referring the case to the social services department. However, the primary aim would be to help Tina and her father resolve their problems, rather than run the risk of irrevocably breaking up the family.

\section{Commentary 3}

\section{Katharine Whitehorn Columnist, The Observer}

The case reminds me very vividly of a case in the magazine World Medicine - a 'confidentiality problem' posed in the form of a question and answer. The question was 'What do you do if a man comes to you who is short-sighted. He is a long-distance lorry driver and he wants you to endorse his application for a driving licence. At the same time he wishes you to sign a fitness certificate for him to carry a firearm, with which he wishes to shoot his daughter, whom he has incestuously made pregnant'. The answer was 'Have him transferred to somebody else's list immediately'.

I think most of the bones of this case have already been exposed by the two previous speakers. I think that, in this case, everybody is probably correct in assuming that the mild aspirin suicide attempt was just as they say, a cry for help. But I think it is worth pointing out that though it is generally felt that people who keep on trying to commit suicide don't really mean it, statistically this is not so. Most people who succeed have made several attempts before, and what could have been an unreal attempt to start with, could be a real attempt the next time around. So one should never too glibly dismiss the possibility of suicide as 'just a cry for help' - if only because of human inefficiency. A friend of a friend of mine was given to doing this sort of thing, she was a model girl, and she finally did commit suicide, but her friend said 'I'm sure she didn't mean to' when actually she did mean to. I'm simply saying that in this case, maybe the suicide attempt wasn't very serious, but it is never a good idea to assume that too readily.

I think these strategies for getting hold of the father and talking to him are absolutely excellent, but one of the things you might consider doing is in some way building up the girl's confidence, so that she herself can say to the father 'Look, I haven't said anything this time, but if you ever do it again I'm going to spill the beans'. The reason I say this is because I wrote recently about this subject after a particular case had been in the news; and I had an interesting letter from a small group called Survivors of Incest. These were people whose whole lives had been spoiled by incestuous incidents, and they said that most people's idea is to try to keep this under wraps because it breaks up the family and does all the things that have already been suggested. They said 'We want to get it about that girls, or boys for that matter, who are suffering from this sort of thing should, in later life, expose what has happened; because then it might act as some kind of deterrent. The father - it is very often the father - or whoever, would know that, even if the girl was too scared to talk about it now, given three years, five years, seven years it would catch up with him'. This might cause at least some fathers to think twice about incest; although obviously the trouble here is that it happens when he is drunk. I appreciate and applaud encouraging him to look for a job, but we all know that isn't necessarily simply a prelude to getting a job; if the solution depends merely on him ceasing to be unemployed, then I don't think it is a very realistic one.

On the three trick questions at the end, if she is pregnant, $\mathrm{OK}$, she needs an abortion and I don't know what the set-up is here. If you have got a whole lot of Life supporters and Catholic nurses on your staff, you might do better to recommend her to the Pregnancy Advisory Service and not risk the whole thing going wrong half-way along the line or ending up in court yourself.

Secondly, about these ears. Maybe the ears were put in as an optional extra when it was written up, but it does seem very likely that the ears were irrelevant in this case. But I would just like to put in a slight word of caution. It is assumed, psychiatrically, that if you come 
along and say that you have a perfectly hideous nose or you have a damaging birthmark that it's a cry for help - that you have a psychiatric problem. But if this does crop up in your clinics later, I would beg you to have a look at the people and see what they really do look like; because I have better evidence of this than you might suppose. Claire Rayner, who handles a vast quantity of post on various women's magazines, a lot of it from teenagers, and does advice columns in a variety of situations, says that the accepted wisdom is that people want cosmetic surgery because they have another problem and that they would not in fact be any happier if they got their birthmarks removed and their noses straightened. She says the case is not proven; because she has a great number of letters from people who have had such things done, and it has made all the difference. And I just invite you to think, if you will, of the sexual situation of a girl who has an extremely obvious purple birthmark, say on the inside thigh; and to wonder how likely she is to be leading a normal sexual life by the time she is 25 . And if you have got a big conk, a terribly big nose, well $\mathrm{OK}$ it is a terrible problem. A woman goes to her GP and she says 'Look, I've got this terrible nose and it has stopped me from ever being happy'. If he has got an even worse nose he won't refer her. There is also a detestable double bind which I will invite you, when you are qualified, to sort out. There are a lot of cowboy firms doing cosmetic surgery and doing untold damage. There is an official list of good cosmetic surgeons, whether they do it privately or are consultants in the National Health Service. But this list only goes to general practitioners, so if your own general practitioner doesn't think you ought to have cosmetic surgery, you will not get access to the list; so you may go off to a cowboy who will make it even worse. Now, I simply say: these ears may be irrelevant, but do not assume that all requests for cosmetic surgery will not make the patient any happier. It just ain't so.

As for the girl, if she has obviously been sexually assaulted in a violent manner as well as the mere sexual advance, I agree that running dad in would be the worst option if you could conceivably avoid it. The girl of course will feel the most appalling guilt herself at having done this to a father whom she does, in some sense, love still, and if John was taken away into care she would also feel guilty about that, so she will crop up again at a later clinic when she will tell you about it. It seems to me that the problem obviously needs a social solution, and I wonder if the social solution must be either that you simply refer it to the social services and tell all; or that you have to cope with it both medically and psychiatrically. There might be a third one: to install in the house where they have been living, an extra person. Would it not be possible to approach the social services on the grounds that this girl is obviously absolutely overwrought by her maternal role, missing out on all the fun at school, that what she needs is a bit of female companionship and a bit of help? Most social services have a great many homeless grannies on their

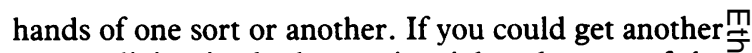
woman living in the house, it might take care of the whole thing (or a great part of it), and you wouldn't? necessarily need to tell the social services the whole $\overrightarrow{\bar{s}}$ story. I don't know whether that is an answer, but if thetwo possibilities with which you are confronted are듬 either 'tell the social services' or 'do nothing', and these $\overline{\bar{s}}$. seem to be equally dire possibilities, I would just like toळ suggest that there might be a third one.

\section{Commentary 4}

Alastair Campbell Associate Dean, Faculty of Divinity, University of Edinburgh

In my view this case raises three separate but related issues of moral concern:

1. A conflict between a paternalistic and non-음 paternalistic approach to Tina; 2 . The question of who, in this case, is the patient; and 3. Uncertainty about the degree of seriousness in the situation.

\section{Paternalism/autonomy}

The first moral issue raised by this case is the treatmento of Tina as a person in her own right, as opposed to treating her as a minor (as she certainly is in law), still dependent upon her parent(s). Obviously her mother is incapable of safeguarding her interests and her $\stackrel{\odot}{\circ}$ father, who in normal circumstances would be the person to be approached, is himself part of the problem. This leaves those dealing with Tina with two alternatives: a) the psychiatrist should regard himself as in loco parentis, seeking (more actively than he might do with an adult patient) to provide care and protection for Tina by whatever means are practicable. This could entail breaking confidence by contacting the social 3 . work department of the local authority in an attempt to mobilise proper assistance for Tina and her younger? brother; or alternatively b) the psychiatrist should treato Tina as an autonomous individual whose expressed desire to return home should be respected and whoseo revelations of what was happening at home should be kept confidential unless she agrees to their being. passed on to someone else. Neither of these alternatives $N$ seems particularly desirable - that, of course, is why N there is a moral dilemma! The first alternative mayo mean creating much more unhappiness for Tina in the name of helping and it is quite likely to undermine her trust in all the professionals seeking to help her. But $\stackrel{+\infty}{+}$ the second alternative ignores the cry for help of the suicide attempt and seems to disregard the fact that the crimes of incest and of intercourse with a minor have $\stackrel{\sim}{\mathbb{}}$ been divulged to the psychiatrist. Can he justifiably seek only to persuade his patient in such serious circumstances?

An answer to the dilemma may be sought by looking carefully at the moral concept of autonomy. This is a relative, not an absolute term. At different stages of oufo 
life and in differing circumstances we possess different degrees of autonomy. Moreover our autonomy may be enhanced or hazarded by the actions of others. Tina, by virtue of the heavy responsibility she has had to assume, has gained more self-direction than might be expected from other children of her age. This should be respected and enhanced. At the same time her lack of freedom, especially in relation to the painful and ambivalent relationship with her father, must be recognised. Her inability (at her young age) to foresee the consequences for herself of returning to this fraught home situation must lead us to treat her as certainly in need of some paternalistic guidance. Paternalism need not be seen as necessarily bad. It can be a helpful protective device which releases the other person from unbearable responsibility.

So I think it should be explained to Tina that, in her own interests, she will not yet be discharged from the hospital. Instead the psychiatrist should offer to discuss with her how she and her father might be helped so that they can try to work out something together. In return the psychiatrist could promise to find some medical excuse for keeping her in, and could agree not to divulge to her father (or to anyone else) the information she had given him, unless she specifically asked him to do so. This approach offers a mixture of paternalistic support and the encouragement of autonomy.

\section{Who is the patient?}

A second major issue relates specifically to the father. He is clearly a very unhappy man who also needs help, but he is not the psychiatrist's patient. What should be done? It seems that the psychiatrist is the only person who has a possibility of some access to him. Therefore, he should contact him as quickly as possible in order to discuss his daughter's future welfare. This can (and should) be done without betraying any confidence which Tina wants safeguarded. If Tina is willing, the question of cosmetic surgery could be a pretext for a frank discussion of the father-daughter relationship. Another avenue might be the mother's illness. In any event, the father should be given the opportunity of becoming a 'patient' in an informal sense.

\section{Degrees of seriousness}

These delicate manoeuvres would not be so easy if the hypotheses about pregnancy or vaginal damage turned out to be the case. These are such physical traumas that they seem to force us to take the situation more seriously. However, I have tried to suggest that the situation is already very serious in an emotional sense. Even if Tina is pregnant or is physically damaged by intercourse, the moral dilemma is little different. Her painfully ambiguous relationship with her father is the source of both her pain and her fragile happiness. Her worry about her prominent ears, provoked by her father's comments, is a powerful symbol of that mixture of feeling. She desperately needs his love but is being offered it in a manner which can only damage her, emotionally as well as physically. Those who want to offer relevant help to Tina must keep this painful ambiguity in view, otherwise they may be provoked by their concern at the assaults she has already received into adding yet another - the destruction of what might yet remain of a positive relationship between Tina and her father. To see a situation as serious is not the same as overreacting to it. Indeed, the only real help which professional workers can offer in such disturbed human interactions is their capacity for a detachment which can restore a balanced and pragmatic approach to the future for their clients. Rather than entering the troubled waters with them, they reach out from dry (or at least less wet) land to bring them out of the turmoil. Thus, whatever the degree of physical seriousness, a prime objective in this situation must remain the restoration of a sense of trust and security in this apparently hopeless family setting. Whatever one's feeling about the father, therapy not punishment must remain one's aim.

In all these three areas of comment I suspect I have been in effect repeating the same point: a moral outcome will not be found by espousing extreme solutions. A well hallowed tradition in ethics, the via media, would seem to be the answer, but in this context, I would prefer to describe it as professional poise. 